\title{
EFFECT OF NANO SILVER AS ADDITIVE BY DIFFERENT WAYS TO ACRYLIC DENTURE BASE AND ITS ROLE IN MENOPAUSAL WOMAN MANAGEMENT
}

\author{
Hoda A. Rashad* and Faten A.S. Abutaleb **
}

\begin{abstract}
Background and aim: Polymethyl methacrylate (PMMA) is broadly used as a removable prosthesis denture base. Silver Nano-particles (AgNPs) had been included to PMMA because of their antibacterial homes and higher thermal conductivity, at the same time as it had a destructive effect on the flexural strength and coloration stability that is probably resulted from the inhomogeneous combination. The motive of this research changed into to discover whether the addition of (AgNPs) to PMMA either in liquid form or in powder nation can enhance the flexural strength and the shade balance of PMMA. Also evaluating an edentulous menopausal lady as a multidisciplinary control after wearing a denture made from silver nanoparticles added to (PMMA) denture base.
\end{abstract}

Materials and methods: Fifty specimens of heat cure acrylic resin had been organized for flexural strength and color stability. Twenty-five for each test that become divided into 3 groups. Group 1 was the control group (unmodified acrylic resin specimens) and group 2 turned into Nano silver introduced within the form of powder to the polymer of (PMMA), while group 3 was Nano silver brought in the form of liquid to the monomer of (PMMA). Group 2 and 3 specimens had been break up into subgroups A and B 5 each, with $0.2 \%$, and $0.4 \%$ wt. of Nano silver addition to (PMMA) respectively. A flexural strength was measured via the usage of an Instron regular testing machine. A double beam ultra-violet visible spectrophotometer was checked to the degree of coloration stability. One edentulous menopausal woman that present process treatment below a gynecologist for menopausal signs and symptoms was selected as a case report and received denture made out of silver nanoparticles added to acrylic resin and patient satisfaction became evaluated after 4 months. The results have been gathered tabulated and statically analyzed.

Results: There has been a massive distinction in the flexural power values among all corporations $(\mathrm{p}<0.05)$ relative to the non-changed heat treatment (control group). Acrylic resin samples with $0.2 \%$ in liquid additive form (3A) ended in more flexural power then $0.4 \%$ addition (3B) in comparison to different changed groups .The samples with $0.4 \%$ in powder form(2B) had a lowest

* Prof of Removable Prosthodontics, Prosthodontic department, Faculty of Dentistry, Tanta University ** Assistant Prof of Removable Prosthodontics, Prosthodontic department, Faculty of Dentistry, Tanta University 
flexural strength in comparison to the all groups $(\mathrm{p}<0.05)$. In comparing the color variations $(\Delta \mathrm{E})$ comparable to control group, group $3 \mathrm{~A}$ and group $3 \mathrm{~B}$, showed lowest color variations respectively. At the same time group $2 \mathrm{~A}$ and $2 \mathrm{~B}$ ended in highest shade distinction .

Conclusion: Set up on the effects of this results, modifying PMMA with Nano silver debris led to lower in flexural strength and shade stability, addition of Nano silver particles in liquid shape was higher than powder form as concerning flexural strength and better color difference and the addition percentage of 0.2 became better than 0.4. Menopausal pride turned into higher and her complain became managed with the new denture.

KEY WARDS: Acrylic resin, Nano silver-particle, flexural strength -color stability- menopausal woman

\section{INTRODUCTION}

A denture base material has to possess biocompatibility with the oral tissues, superior mechanical residences, super esthetics and antibacterial effect ${ }^{1}$. An acrylic resin are appreciated for complete denture fabrication due to the noticeably ease manipulation and production methods plus the low value material. Acrylic resin is colorless and transparent at an everyday temperature/ stress values. But, it isn't the suitable material in each property ${ }^{2}$.

One of the top negative aspects of polymethyl methacrylate (PMMA) resin is its low thermal conductivity. Furthermore, flexural fatigue of dentures as manifested with the aid of midline fracture is due to the stress attention around the micro cracks formed in the material due to non-stop programs of small forces ${ }^{3,4}$. Fracture of dentures in carrier has been worried, and several attempts had been made to improve flexural and impact power of PMMA. Researches in those areas aimed to adjust the composition or strengthen the PMMA with other stronger substances for growing new substances with higher houses.

Due to those drawbacks and with the purpose of enhancing the properties of acrylic resin, debris of materials can be introduced to the liquid or powder of acrylic resin and polymeriz ${ }^{5}$. As an instance, incorporating silver materials ${ }^{6}$, alumina and an oxide ceramic ${ }^{7-9}$ has been used. Silver is a metallic with excessive conductivity, its antimicrobial properties have been mentioned in several studies whilst delivered to the denture base inside the form of nanoparticles ${ }^{10,11}$.

Nanotechnology has shared inside the development in substances used in medicinal drug, as it may provide better functionality, due to the nano metric sizes involved silver nanoparticles [AgNPs] that exhibit distinctive properties once they may be carried out to organic structures, in comparison with traditional structures of treatment. The Nano scale lets in the materials the capability to penetrate into distinct organic membranes, which include bacterial cellular walls, thereby increasing bactericidal effect ${ }^{12}$. The Nano scale scope (1-one hundred $\mathrm{nm}$ ) used to symbolize nanoparticles ought to not be considered strict, because of the variations which could exist in the nanoparticle shape, surface location-to-mass ratio and composition ${ }^{13}$.

Nowa days, a greater attention has directed towards the addition of nanoparticles into PMMA to enhance its properties. The residences of polymer Nano composites depend upon the sort of included nanoparticles, their length, and form as well as the awareness and interaction with the polymer matrix ${ }^{14}$. Consequently, a way of incorporating silver nanoparticles (AgNPs) into acrylic resin denture base substances to beautify its fatigue conduct, effect electricity, and thermal conductivity. But, there are some discrepancies among the effects of those studies ${ }^{15}$. 
Improvement of acrylic resin with AgNPs appreciably depends on its concentration. Right concentrations to PMMAcan improve its mechanical characteristics without any detrimental results. because adding AgNPs by 2 wt $\%$ decreased the tensile strength of acrylic resin, AgNPs with 0.2 and a couple of wt $\%$ extended the compressive power of acrylic resins, but increasing AgNPs awareness from $0.2 \mathrm{wt} \%$ to $2 \mathrm{wt} \%$ did not improve compressive energy of acrylic resin drastically. The acrylic resin is a brittle material however at compressive situations behaves like ductile materials ${ }^{16}$.

Esthetic troubles rise up from discoloration of acrylic resin. The addition of a silver compound to acrylic resin as a measure in opposition to odor and bacterial proliferation inside the oral cavity has been studied; however undesirable color adjustments have tended to arise ${ }^{17}$. Coloration balance is a vital belonging of a denture liner to retain its color in distinct surroundings, specifically in long-term use. Color evaluation and its reproduction is one of the most difficult components of dentistry. Visual shade matching is still the primary method for comparing the color and can cause dissatisfying results. Photoelectric tri stimulus colorimeters have the capacity to do away with a number of the variables discovered whilst the visual technique is used completely and offer correct and repeatable measurements ${ }^{18}$.

Menopause is a regular developmental level in a woman's existence accompanied with a massive wide variety of signs starting from physical to psychological. A number of the common oral manifestations are an oral burning sensation with associated mucosal infections, ache, altered flavor perception, and alveolar bone loss. Those signs may additionally unfavorably affect oral health and remedy needs requiring dentists to plot newer techniques that could upload along to the remedy modalities counseled via gynecologists in relieving menopausal women from above symptoms ${ }^{19}$. so innovate methods had been used to assist the menopausal edentulous female to sense hot/cold sensations of food/drinks, thereby giving them relief from ache, higher flavor notion, and remedy from related allergic and candida infections which are commonplace with conventional acrylic base dentures.

As the manner of addition of silver nanoparticles, it's far obvious that the degree of nanoparticles' dispersion within the PMMA matrix is affected by the chemical composition of this acrylic resin. Probable, at excessive concentrations, particle dispersion and chemical interactions among PMMA and AgNPs are low, ensuing in a decrease in tensile electricity. the speculation of this observe became that , to improve dispersion inside the acrylic resin, the AgNPs addition in a liquid form to heat-therapy acrylic resin could bring about extra homogenous mix and higher mechanical homes.

\section{MATERIALS AND METHODS}

The first part of this research was experimental study and conducted in Laboratory of Prosthodontic Department, Faculty of Dentistry, Tanta University. Two denture base materials were used, one of them was heat-polymerized polymethyl methacrylate (PMMA) (Acrostone (A), Anglo-Egyptian Company. Hegaz, Cairo, Egypt, Batch No.505/04) and the other was Nanoparticles of silver (NAg) (Nano Technology Co., Ltd., Egypt (Figure 1) added with concentration $(0.2 \%$, and $0.4 \%)$ to the heat-cured acrylic resin in two forms, powder additive form and liquid additive form. Twenty five specimens with $65 \mathrm{~mm}$ length, $10 \mathrm{~mm}$ width and $3 \mathrm{~mm}$ thickness for flexural strength (figure 2). and twenty five disc-shaped samples, with uniform size of $10 \mathrm{~mm}$ diameter and $2 \mathrm{~mm}$ in thickness for color stability were prepared according to ISO 1567 Standard ${ }^{20}$ (figure 3 ). The samples for each test were divided according to the way and percentage of nanosilver addition to acrylic resin as were shown in table 1 
Preparing samples of group 1 (control group without silver nanoparticles)

Five samples were prepared from heat cure acrylic resin. The acrylic paste was prepared considering manufacturer liquid/powder ratio supplied in powder and liquid forms. The amount of acrylic resin that needed for the five samples was counted and so on the weight of each sample could be estimated which was 0.4 gram (gr).

Preparing samples of group 2 A and B (Addition of Nanoparticles powder to the acrylic resin powder) ${ }^{21}$

The counted amount of $0.2 \%$ and $0.4 \%$ weight of silver nanoparticles (gr) from $0.4 \mathrm{gr}$ which is the sample weight is equal to 0.008 gr and 0.016 gr of silver nanoparticles powder with average size measuring $22 \mathrm{~nm}$ was mixed with heat-cure denture base acrylic powder (PMMA) .The two powders were mixed in a mortar and then in an amalgamator (YDM, China) for two minutes to achieve a mixture with uniform color.

Preparing samples of group 3 A and B (Addition of Nanoparticles liquid to the acrylic resin liquid) ${ }^{22}$

Silver nanoparticles were synthesized through the reduction of silver nitrate (AgNO3) (Merck KGaA, Darmstadt, Hesse, Germany) with sodium citrate (Na3C6H5O7) (Merck KGaA). The aqueous solution of silver nitrate and sodium citrate was kept at boiling temperature for a couple of minutes until the solution turned amber yellow, indicating the formation of colloidal silver nanoparticles, Finally, the solution was cooled in room temperature.

The weight of $1.5 \mathrm{cc}$ silver nanoparticle colloid was $2 \mathrm{gr}$ powders after concentration. The volume of silver nanoparticle colloids for sample preparation was evaluated considering weight percentage of silver nanoparticles in the acrylic samples which was used with powder additive is 0.008 and 0.016 gr for $0.2 \%$ and $0.4 \%$ for each sample respectively.

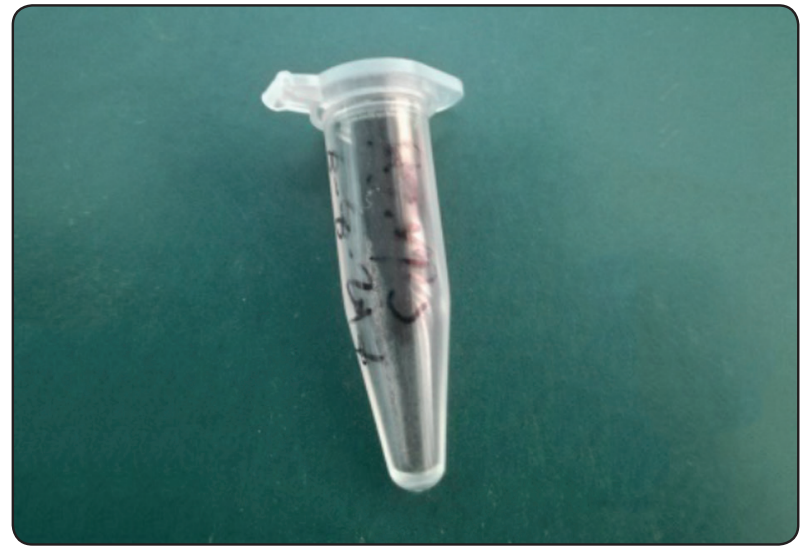

Fig. (1) Showed the Nano silver powder

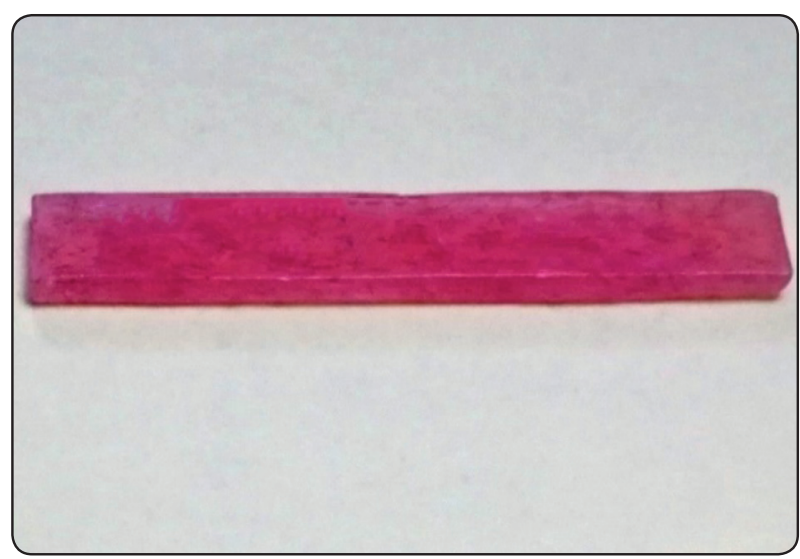

Fig. (2) Specimens of flexural strength

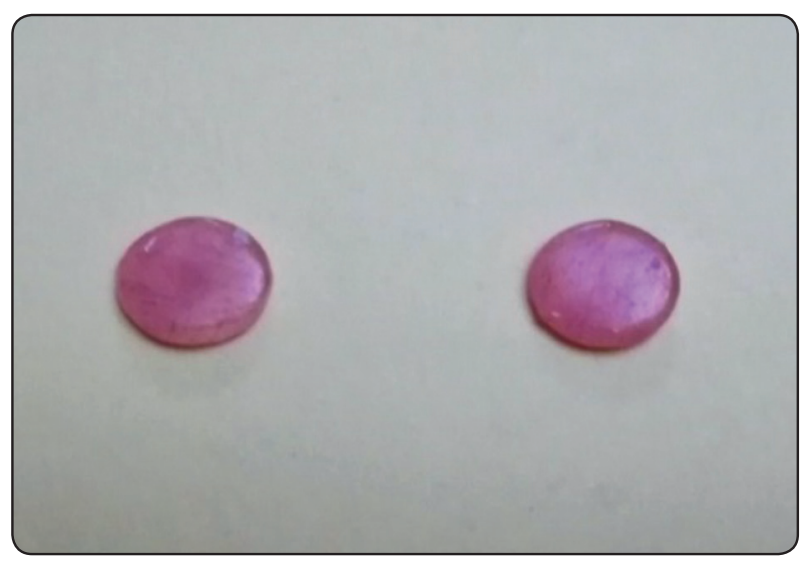

Fig. (3) Specimens for color measurements 
TABLE (1) Showed the groups of sample

\begin{tabular}{|c|l|}
\hline Group 1 & $\begin{array}{l}\text { Control group, acrylic resin without silver } \\
\text { nanoparticles }\end{array}$ \\
\hline Group2A & $\begin{array}{l}\text { Nanosilver added to acrylic resin with } 0.2 \% \text { in } \\
\text { powder form }\end{array}$ \\
\hline Group2B & $\begin{array}{l}\text { Nanosilver added to acrylic resin with } 0.4 \% \text { in } \\
\text { powder form }\end{array}$ \\
\hline Group3A & $\begin{array}{l}\text { Nanosilver added to acrylic resin with } 0.2 \% \text { in } \\
\text { liquid form }\end{array}$ \\
\hline Group3B & $\begin{array}{l}\text { Nanosilver added to acrylic resin with } 0.4 \% \text { in } \\
\text { liquid form }\end{array}$ \\
\hline
\end{tabular}

The required volume of colloid for preparation of each acrylic samples containing $0.2 \%$ silver nanoparticles is equal to: 0.008 gr silver nanoparticles $\times(1.5 \mathrm{cc}$ of silver nanoparticle colloids $) /(2$ gr of silver nanoparticle colloids $)=0$. $006 \mathrm{cc}$.Regarding the above-mentioned equations, the required volume of colloid for preparing one sample of $0.2 \mathrm{wt} \%$ and $0.4 \mathrm{wt} \%$ (mass fraction) is $0.006 \mathrm{cc}$ and $0.012 \mathrm{cc}$ respectively .

Then, the powder and liquid with nanoparticles solution were mixed according to manufacture recommendation. The heat cured acrylic resin was processed; finished and polished. The samples for each test were scheduled according to the addition technique and additive percentage. All acrylic specimens were labeled and immersed in distilled water and stored at $37^{\circ} \mathrm{C}$ for 1 -week.

One edentulous menopausal woman that undergoing treatment under a gynecologist for menopausal symptoms was selected as a case report and reported with the chief complaints of burning sensation in the oral cavity especially in anterior portion of mouth, frequent redness of mucosa, inability to sense temperature changes of food, and recurrent allergic and microbial infections with present acrylic dentures. Medical history revealed that the patient was undergoing treatment under a gynecologist for menopausal symptoms. Dental history revealed patient was edentulous since 2 years and had been experiencing problems with current denture since 1 year. New complete denture constructed from silver nanoparticles added in liquid form with $0.2 \%$ to heat cure acrylic resin and patient satisfaction about the previous complain was evaluated after four months .

\section{Measurement and analysis}

\section{Flexural analysis test ${ }^{23}$}

The flexural strengths of the specimens were determined using a 3-point bending testing device in a universal testing machine (Model LRX-plus; Lloyd Instruments Ltd., Fareham, UK) ( Figure4) with a load cell of $5 \mathrm{kN}$ and data were recorded using computer software (Nexygen-MT; Lloyd Instruments). The device consisted of a loading wedge and a pair of adjustable supporting wedges placed $50 \mathrm{~mm}$ a part .The specimens were centered on the device in such a way that the loading wedge, set to travel at a crosshead speed of $5 \mathrm{~mm} / \mathrm{min}$, engaged the center of the upper surface of the specimens. Specimens were loaded until fracture occurred.

The calculation of FS (MPa) was guided by the formulae:

$$
\mathrm{FS}=3 \mathrm{~F}(\mathrm{~L}) / 2 \mathrm{wh} 2
$$

Where; $\mathrm{F}$ is the maximum load at the point of fracture $(\mathrm{N}), \mathrm{L}$ is the span $(\mathrm{mm}), \mathrm{w}$ is the width of the sample (mm) and $\mathrm{h}$ its height (mm).

\section{Color Assessment ${ }^{24}$}

A double beam ultra-violet visible spectrophotometer (UV-Vis. UV 3101 PC, Shimadzu scanning spectrophotometer) (Figure 5) was used. A sphere attachment was used for the measurement. The sample was hold in the attachment by a holder. (X, Y and Z) value was computed relative to the CIE 1931 Commission International L'Eclairage and relative to particular light source. The ratios of each value of a color to their sum are called 
chromatically coordinate $(\mathrm{x}, \mathrm{y}, \mathrm{z})$ i.e.:

$$
\begin{aligned}
& x=X /(X+Y+Z) \\
& y=Y /(X+Y+Z) \\
& z=(1-[X+Y])
\end{aligned}
$$

A C1E L*, a* and $b^{*}$ color order system, provided a useful standardization technique for color difference assessment. Difference between two colors was determined from the color difference formula:

$\Delta \mathrm{E}\left(\mathrm{L}^{*}, \mathrm{a}^{*}\right.$ and $\left.\mathrm{b}^{*}\right)=\left[(\Delta \mathrm{L})^{2}+(\Delta \mathrm{a})^{2}+(\Delta \mathrm{b})\right.$ $\left.{ }^{2}\right]^{1 / 2}$ Where $L^{*}, a^{*}$ and $b^{*}$ depended on values $(\mathrm{X}, \mathrm{Y}, \mathrm{Z})$ of the specimens and a perfectly white object where $\mathrm{L}^{*}$ corresponds to the value in the Munsell system which represents the lightness coordinate, while $\mathrm{a}^{*}$ is the red-green coordinate and $b^{*}$ is the yellow-blue coordinate. The color of each opposing pair is indicated by the positive and negative values of $a^{*}$ and $b^{*}\left(+a^{*}=\right.$ redness, $-a^{*}=$ greenness, $\quad+b^{*}=$ yellowness, $\quad-b^{*}=$ blueness $)$. The values $(\mathrm{X}+\mathrm{Y}+\mathrm{Z})$, the chromatically coordinate $(\mathrm{x}, \mathrm{y}, \mathrm{z})$. The $\mathrm{L}^{*}, \mathrm{a}^{*}$ and $\mathrm{b}^{*}, \Delta \mathrm{E}, \Delta \mathrm{L}, \Delta \mathrm{a}$, and $\Delta \mathrm{b}$ were automatically calculated. The results were recorded with a computer color matching system (CCM).

Statistical analysis was performed by Statistical Package for Social Science (SPSS) computer software (SPSS 16.0, SPSS Inc., Chicago, USA).

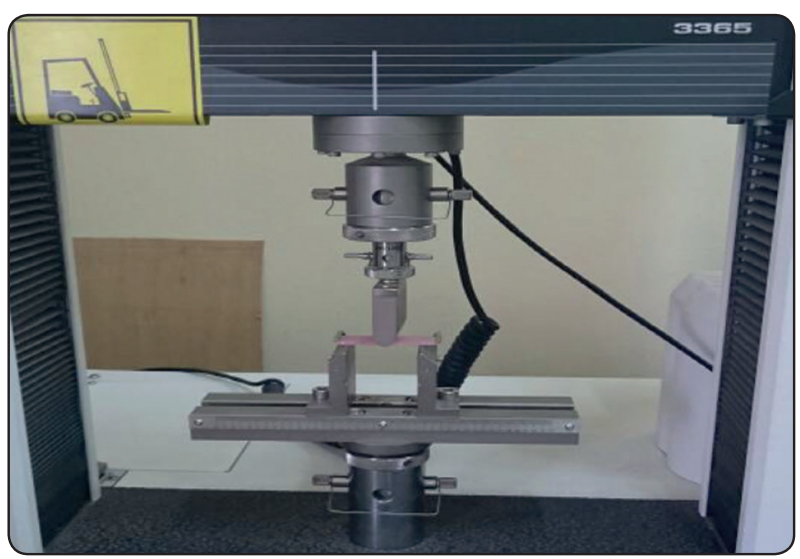

Fig. (4) Universal testing machine

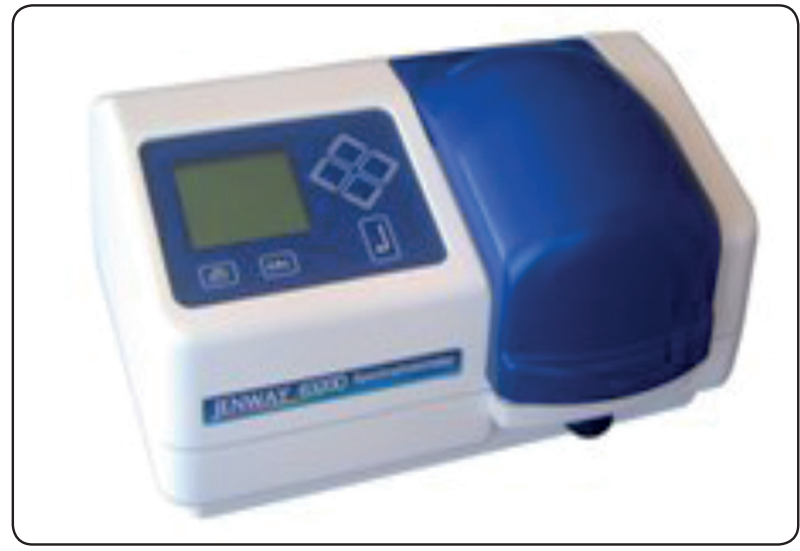

Fig. (5) Spectrophotometer

One-way ANOVA was used to determine whether significant differences existed between the means of the various experimental groups. Tukey test was employed at the chosen level of probability $(\mathrm{p}<0.05)$ to determine if the means were significantlydifferent from each other

\section{RESULTS}

As shown in table 2 graph 1 , there were significant differences in the mean flexural strength values among all groups compared to the control group $(\mathrm{p}<$ 0.05). The results of multiple comparison tests for flexural strength of samples in all groups showed that, acrylic resin samples with $0.2 \%$ additive in liquid form (3A) resulted in more flexural strength than other groups followed by $0.4 \%$ liquid form addition (3B). While the addition of $0.4 \%$ in powder form (2B) had a significantly lower flexural strength compared to the other groups.

As regards color difference as shown in table 3 graph 2 , there was a significant difference $(\mathrm{P}<0.05)$ between groups (1,2 and 3) .In comparison to heatcured acrylic resin without additives ( non-modified control group), addition of nanoparticles of silver in liquid state to heat-cured acrylic resin with $0.2 \%$ (group 3A) showed lowest mean color differences $(\Delta \mathrm{E})$ followed by $0.4 \%$ (group 3B) Addition of 
Nano silver in the form of powder by $0.4 \%$ (group 2B ) resulted in highest color difference followed by $0.2 \%$ (group $2 \mathrm{~A}$ ) .

\section{Satisfaction of menopausal woman}

The patient received complete denture constructed from Nano silver added to heat cure with $0.2 \%$ in liquid form .As it was the nearest flexural strength and color difference comparable to unmodified heat cure. Patient reported relief of complained menopausal symptoms, as better awareness with hot and cold, no more redness and comfortable denture .

TABLE (2) Showed the means and standard deviations of flexural strengths of the tested groups (in MPa)

\begin{tabular}{|c|c|c|c|}
\hline Group & Mean & SD & P \\
\hline Group 1 & 77.63 & 7.90 & \multirow{2}{*}{0.000} \\
\hline Group 2A & 52.4883 & 13.21 & \\
\hline Group 2B & 35.1250 & 9.45 & \\
\hline Group 3A & 66.230 & 4.208 & \\
\hline Group 3B & 62.0983 & 12.98 & \\
\hline
\end{tabular}

Statistically significant at $p \leq 0.05$

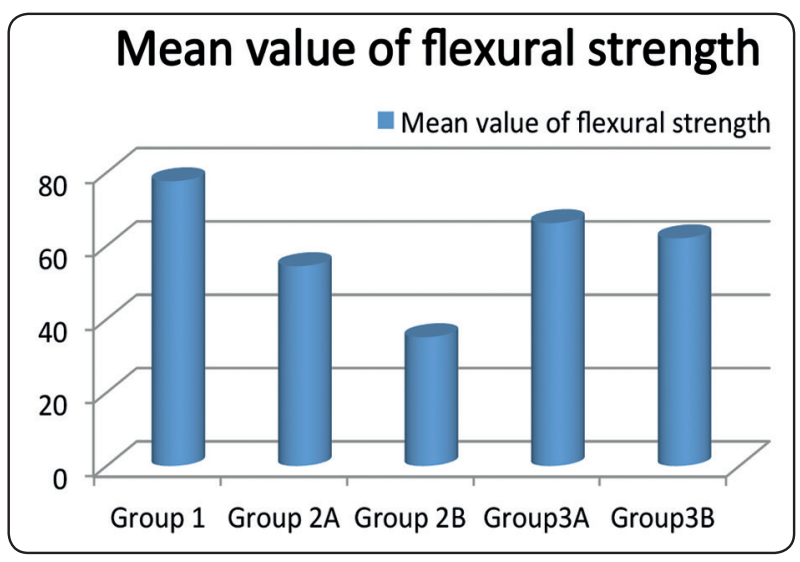

Graph (1) showed the means value of flexural strengths of the tested groups (in $\mathrm{MPa}$ )
TABLE (3) Showed the mean and standard deviation of color differences of acrylic resin with AgNps incorporation

\begin{tabular}{|c|c|c|c|}
\hline Group & Mean & SD & P \\
\hline Group1 & 1.55 & 0.29 & 0.000 \\
\hline Group2A & 3.73 & 0.20 & \\
\hline Group2B & 4.82 & 2.53 & \\
\hline Group3A & 2.33 & 0.25 & \\
\hline Group3B & 2.80 & 0.20 & \\
\hline
\end{tabular}

Statistically significant at $p \leq 0.05$

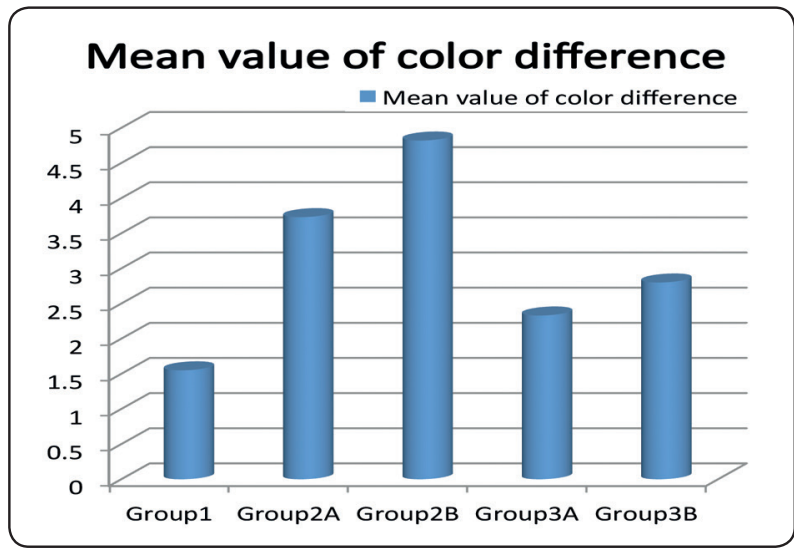

Graph (2) Showed the mean value of color differences of acrylic resin with $\mathrm{AgNps}$ incorporation

\section{DISCUSSION}

Many studies have tried to improve the houses of acrylic denture base through adding extraordinary materials. The use of silver as an additive due to its high thermal conductivity could enhance the low thermal conductivity of acrylic resin denture. Moreover, it's been validated that silver has no dangerous impact on oral mucosa and may even decrease the adhesion of candida albicans and exert antimicrobial effects ${ }^{10}$.

As said through Balan et $\mathrm{a}^{25}$, for the coaching of Nano composites, approaches have been advanced either by mixing nanoparticles with the polymer or including nanoparticles to the monomer. In the 
present study, the 2 different including methods have been evaluated ${ }^{25}$.

The additive percentage of silver nanoparticles in this research was $0.2 \%$ and $0.4 \%$ as the nanoparticles addition must be certainly quantified such that the amount used does now not purpose damaging on the mechanical and thermal residences of the acrylic base of entire dentures ${ }^{26}$. It revealed that the effect of AgNPs on the flexural strength of PMMA relied on numerous elements which include the type of acrylic resin and the attention of nanoparticles ${ }^{27,28}$.

It's miles important that the content material of Nano additives is of vital importance, even in modified polymeric substances. The nature of those particles is associated with their size and crystal type. The multiplied floor vicinity in Nano-sized debris reasons extra powerful touch with microorganisms and subsequent stepped forward antimicrobial property ${ }^{29}$. On this research, the size of used silver nanoparticles ranged from 10 to a hundred $\mathrm{nm}$, as it has been demonstrated that larger fillers in addition lower the tensile and flexural power. In addition, in case of the usage of low concentrations, small particle sizes have to be selected for higher distribution among the PMMA particles ${ }^{30}$.

Low concentration of silver might reduce material expenses and less monomer could be wanted while mixing with acrylic powder. Consequently, the mechanical properties of the polymer could now not be compromised ${ }^{21}$. Chladek et al ${ }^{27}$ reported that the mechanical and physical properties of the composite are influenced by using silver nanoparticle attention. Additionally they showed that mechanical properties of composites decreased through growing silver nanoparticles.

The outcomes of this study indicated that incorporation of AgNPs extensively reduced the flexural strength of PMMA in all studied group that is probably attributed to Nano-silver particle size. This could additionally promote the chances of void formation from entrapped air and moisture and incomplete wetting of the nanoparticles by using resin. Therefore the net impact of embedding silver nanoparticles became to weaken the polymer. The results are in agreement with Solhi et al ${ }^{31}$, Zukas, et $\mathrm{al}^{32}$ and Ghaffari et $\mathrm{al}^{33}$.

Despite the extensive decrease in flexure strength with Nano silver addition, the maximum similar strength to control group became the samples wherein the addition become in liquid form and of percent $0.2 \%$ due to the distribution of particles is greater equal than if mixed in powder shape into acrylic powder. That is in agreement with Mahross and Baroudi ${ }^{34}$ and confrontation with the technique of Hamedi-rad et $\mathrm{al}^{6}$, as they displaying that, the proportional quantities of acrylic resin powder and Nano silver decided via weighting with a virtual scale were mixed together by an amalgamator to attain a homogenous combination of PMMA and Nano silver powder. The of percentage $0.2 \%$ become better than of percentage $0.4 \%$ as pronounced with Balan et $\mathrm{al}^{25}$. The lower in mechanical properties at higher concentrations might be attributed to the attributed to the quality of dispersion of nanoparticles with different surface characteristics within the resin matrix ${ }^{22}$.

Chatterjee ${ }^{35}$ stated that, as the Ag mapping consequences showed growing, AgNps content material ended in agglomeration of these nanoparticles and growing impurity motion of nanoparticles. Impurities or particulate agglomerate compounds act as pressure concentration centers within the matrix and unfavorably decrease mechanical properties of resin. Surely, unmodified nanoparticles or particles modified with polar or non-polar amine derivatives exhibit different effects within the resin matrix with an increase in concentration ${ }^{33}$.

The American Dental Association ${ }^{36}$ recommends the use of the global de l'eclairage (cie $1^{*}, a^{*}$ and $\left.b^{*}\right)$ for the shade differential which represents the overall colour difference between the two measurements in cie $1^{*}, a^{*}$ and $b^{*}$ colour space is considered to be a higher indicator for evaluating the color stability of dental materials ${ }^{37}$. 
All groups of heat-cured acrylic resin with an addition of nanoparticles of silver (Nag) showed coloration differences $(\Delta \mathrm{E})$ values higher than that control group (unmodified acryl) .The $0.4 \%$ powder form nanoparticles of silver have considerably highest suggest color differences observed by way of $0.2 \%$ nanoparticles of silver then 0.2 and $0.4 \%$ nanoparticles liquid form of silver contained heatcured acrylic resin.

The color difference values of $\Delta \mathrm{E}$ between 0 and a pair of represent insensible color variations, while price inside the variety of 2 to a few constitute realistic color variations. The existing results used nanoparticles of silver (Nag) \% due to the fact their large surface vicinity and small particle size ought to enable them to launch greater $\mathrm{Ag}$ ions at a low filler level. thereby lowering $\mathrm{Ag}$ nanoparticle concentration is higher for efficacy and shade stability ${ }^{38}$, as the Ag ions within the resin agglomerated to shape nanoparticles that became a part of the resin that have an destructive effect on the acrylic resin properties as flexure strength and coloration stability ${ }^{39}$.

It becomes vital that the dentist is equipped with appropriate communication capabilities other than specialty/technical competencies required for creating an entire denture. it became discovered in one of the studies that postmenopausal women have been now not aware of their periodontal health and the risks worried to their systemic fitness and therefore authors suggested growing taskforce comprising of periodontists, generalists, verbal exchange experts ${ }^{40}$.

\section{CONCLUSION}

Adding Nano silver debris to PMMA ended in a lower in flexural energy and coloration balance ,addition of Nano silver particles in liquid shape became better than powder shape as regarding flexural strength and shade difference and the addition percentage of 0.2 became better than 0.4 .
Menopausal delight become better and her complain become managed with the brand new denture. Similarly research is wanted to quantify the filler distribution inside the polymer matrix

\section{REFERENCES}

1. Tuna SH, Keyf F, Gumus HO, Uzun C. The evaluation of water sorption/solubility on various acrylic resins. Eur J Dent. 2008;2:191-197.

2. Mahrous $\mathrm{H}$ and Ebrahim M. Effect of adding nanoparticles of silver on color stability of acrylic resin denture base material .Egypt Dental Journal 2013;59: 3939:3944.

3. Meng TR, Jr, Latta MA. Physical properties of four acrylic denture base resins. J Contemp Dent Pract. 2005;6:93-100.

4. Hirajima Y, Takahashi H, Minakuchi S. Influence of a denture strengthener on the deformation of a maxillary complete denture. Dent Mater J. 2009;28:507-512.

5. Yadav NS, Elkawash H. Flexural strength of denture base resin reinforced with aluminum oxide and processed by different processing techniques. J Adv Dent Res 2011;2:33-36.

6. Hamedi-Rad F, Ghaffari T, Rezaii F, Ramazani A. Effect of nanosilver on thermal and mechanical properties of acrylic base complete dentures. J Dent(Tehran) 2014;11:495-505.

7. Atla J, Manne P, Gopinadh A, Sampath A, Muvva SB, Kishore K, et al. The effect of $\mathrm{Al} 2 \mathrm{O} 3$ addition on the thermal diffusivity of heat activated acrylic resin. J Clin Diagn Res 2013;7:1797-1806.

8. Jagger D, Harrison A, Jandt KD. The reinforcement of dentures. J Oral Rehabil. 1999;26:185-194.

9. Ghaffari T, Hamedi-rad F. Effect of Silver Nano-particles on Tensile Strength of Acrylic Resins .; J Dent Res Dent Clin Dent Prospect 2015; 9:40-43. I

10. Chladek G, Mertas A, Barszczewska-Rybarek I, Nalewajek T, Zmudzki J, Król W. Antifungal activity of denture soft lining material modified by silver nanoparticles-a pilot study. Int J Mol Sci 2011; 12: 4735-4744.

11. Monteiro DR, Gorup LF, Takamiya AS, de Camargo ER, Barbosa DB. Silver distribution and release from an antimicrobial denture base resin containing silver colloidal nanoparticles. J Prosthodont 2012; 21: 7-15.

12. Kohler N, Sun C, Wang J, Zhang M. Methotrexatemodified super paramagnetic nanoparticles and their intracellular uptake into human cancer cells. Langmuir. 2005;21:8858-8864. 
13. Lövestam GH, Rauscher H, Roebben G, Sokull Klüttgen B, Gibson N, Putaud J P et al. : Considerations on a Definition of Nanomaterial for Regulatory Purposes. JRC Reference Reports. Italy. 2010; Pp7,8.

14. Jordan J, Jacob KL, Shart MA. Experimental trends in polymer Nano-composites - A review. Mater Sci Eng. 2005;393:1-11.

15. Yu B, Ahn JS, Lim JI, Lee YK. Influence of TiO2 nanoparticles on the optical properties of resin composites. Dent Mater. 2009; 25: 1142-1147.

16. GhaffariT, Hamedirad F and Ezzati B . In Vitro Comparison of Compressive and Tensile Strengths of Acrylic Resins Reinforced by Silver Nanoparticles at $2 \%$ and $0.2 \%$ Concentrations . J Dent Res Dent Clin . 2014; 8:204-209.

17. Koichi Y, Harumi A, Takaichi Y: Color change capacity of dental resin mixed with silver methacrylate caused by light irradiation and heating. Dent Mater J 2009;28:324-337.

18. Mutlu-Sagesen L, Ergun G, Özkan Y, Bek B. Color stability of different denture teeth materials: an in vitro study. J Oral Sci 2001;43:193-205.

19. BhatiaV, Bhatia G, Jain N, Jadon AK. An innovative metal base denture design for a 55-year-old menopausal woman J Nat Sci Biol Med. 2013; 4: 468-472.

20. International Organization for Standardization. Specification 20795-1: $2^{\text {nd }}$ ed . Denture Base polymer Geneva, Switzerland, 2013: 1035.

21. Ghafari T, Hamedi Rad F, Ezzati B. Does Addition of Silver Nanoparticles to Denture Base Resin Increase Its Thermal Conductivity? J Dent Sch 2014; 32: 139-144.

22. Ghahremanloo A, Movahedzadeh M. The Effect of Silver Nano Particles on Candida Albicans and Streptococcus Mutans in Denture Acrylic Resins. J Dent Mater Tech 2016; 5:23-30.

23. Machado C, Sanchez E, Azer SS, Uribe JM. Comparative study of the transverse strength of three denture base materials. J Dent 2007;35:930-933.

24. ANSI /ADA Specification No.27. Direct filling resins. American National Standards Institute, American Dental Association. Revised 1993.

25. Balan L, Schneider R, Lougnot DJ. A new and convenient route to polyacrylate/silver nanocomposites by lightinduced cross-linking polymerization. Prog Org Coat. 2008;62:351-357.

26. Gorup LF, Takamiya AS, de Camargo ER, Barbosa DB. Silver distribution and release from an antimicrobial denture base resin containing silver colloidal nanoparticles. J Prosthodont 2012; 21: 7-15. 19.
27. Chladek G, Kasperski J, Barszczewska-Rybarek I, Żmudzki J. Sorption, solubility, bond strength and hardness of denture soft lining incorporated with silver nanoparticles. Int J Mol Sci 2013; 14: 563-574.

28. Sodagar A, Kassaee M, Akhavan A, Javadi N, Arab S, Kharazifard MJ. Effect of silver nano particles on flexural strength of acrylic resins. J Prosthodont Res 2012; 56: 120124. 21

29. Prabhu S, Poulose EK. Silver nanoparticles: mechanism of antimicrobial action, synthesis, medical applications, and toxicity effects. International Nano Letters. 2012; 2:1-10.

30. Messersmith PB, Obrez A, Lindberg S. New acrylic resin composite with improved thermal diffusivity. J Prosthet Dent 1998; 79: 278-284.

31. Solhi L, Atai M, Nodehi A, Imani M. A novel dentin bonding system-containing poly (methacrylic acid) grafted nanoclay: synthesis, characterization and properties. Dent Mater. 2012; 28: 1041-1050

32. Žukas T, Jankauskaite V, Žukienė K. The Influence of Nanofillers on the Mechanical Properties of Carbon Fibre Reinforced Methyl Methacrylate Composite. Mater Scienc. 2012; 18: 250-255.

33. Ghaffari T., Barzegar A., Hamedi Rad F., Moslehifard E. Effect of Nanoclay on Thermal Conductivity and Flexural Strength of Polymethyl Methacrylate Acrylic Resin. J Dent Shiraz Univ Med Sci., 2016 June; 17: 121-127.

34. Mahross H Z, and Baroudi K. Effect of silver nanoparticles incorporation on viscoelastic properties of acrylic resin denture base material. Eur J Dent. 2015 ;9: 207-212.

35. Chatterjee A. Effect of nanoTiO2 addition on poly methyl methacrylate. J Appl Polym Sci2010;16:3396-407.

36. Conay S, Cehreli M: The effect of current bleaching agents on the color of light polymerized composites in vitro. $\mathrm{J}$ Prosth Dent 2003; 89: 474-478.

37. Heydecke G, Zhang F, Razzoog M: In vitro color stability of double-layer veneers after accelerated aging. J Prosth Dent 2001; 85: 551-557.

38. Cheng Y, Zeiger D, Howarter J, Zhang X, Lin N, Antonucci $\mathrm{J}$, et al: In situ formation of silver nanoparticles in photo cross linking polymers. J Bio Mat Res2011;97B:124-131.

39. Cheng L, Zhang K, Melo M, Weir M, Zhou X, Xu H: Antibiofilm dentin primer with quaternary ammonium and silver nanoparticles. J Dent Res 2012;91:598-604.

40. Palomo L, Chitguppi R, Buencamino MC, Santos D, Thacker $\mathrm{H}$. A need to educate postmenopausal women of periodontal health. J Indian Soc Periodonto. 2013; 17: 225-227. 